19. Holmberg O, Malone J, Rehani M, et al. Current issues and actions in radiation protection of patients. Eur J Radiol 2010;76:15-19

20. Berrington de González A, Mahesh M, Kim KP, et al. Projected cancer risks from computed tomographic scans performed in the United States in 2007. Arch Intern Med 2009;169:2071-77

21. Meer AB, Basu PA, Baker LC, et al. Atlas SW exposure to ionizing radiation and estimate of secondary cancers in the era of high-speed CT scanning: projections from the Medicare population. J Am Coll Radiol 2012;9:245-50

22. Pearce MS, Salotti JA, Little MP, et al. Radiation exposure from CT scans in childhood and subsequent risk of leukaemia and brain tumours: a retrospective cohort study. The Lancet 2012;380:499505

23. ICRP. Managing Patient Dose in Computed Tomography: ICRP Publication 87. Oxford, UK: Elsevier Science; 2002

24. Engelbrecht V, Malms J, Kahn T, et al. Fast spin-echo MR imaging of the pediatric brain. Pediatr Radiol 1996;26:259-64

25. Penzkofer AK, Pfluger T, Pochmann Y, et al. MR imaging of the brain in pediatric patients: diagnostic value of HASTE sequences. $A J R$ Am J Roentgenol 2002;179:509-14

26. Forbes KP, Pipe JG, Karis JP, et al. Brain imaging in the unsedated patient: comparison of periodically rotated overlapping parallel lines with enhanced reconstruction and single-shot fast spin-echo sequences. AJNR Am J Neuroradiol 2003;24:794-98

27. Ashley WW Jr, McKinstry RC, Leonard JR, et al. Use of rapid-sequence magnetic resonance imaging for the evaluation of hydrocephalus in children. $J$ Neurosurg 2005;103(2 suppl):124-30

28. Iskandar BJ, Sansone JM, Medow J, et al. The use of quick-brain magnetic resonance imaging in the evaluation of shunt-treated hydrocephalus. J Neurosurg 2004;101(2 suppl):147-51

29. Liang L, Korogi $Y$, Sugahara T, et al. Detection of intracranial hemorrhage with susceptibility-weighted MR sequences. AJNR Am J Neuroradiol 1999;20:1527-34

30. Jones KM, Mulkern RV, Mantello MT. Brain hemorrhage: evaluation with fast spin-echo and conventional dual spin-echo images. Radiology 1992;182:53-58

31. Miller JH, Walkiewicz T, Towbin RB, et al. Improved delineation of ventricular shunt catheters using fast steady-state gradient recalled-echo sequences in a rapid brain MR imaging protocol in nonsedated pediatric patients. AJNR Am J Neuroradiol 2010;31: $430-35$

32. Shellock FG, Wilson SF, Mauge CP. Magnetically programmable shunt valve: MRI at 3-Tesla. Magn Reson Imaging 2007;25:1116-21

33. Nakashima K, Nakajo T, Kawamo M, et al. Programmable shunt valves: in vitro assessment of safety of the magnetic field generated by a portable game machine. Neurol Med Chir (Tokyo) 2011;51:635-38

34. Nomura S, Fujisawa H, Suzuki M. Effect of cell phone magnetic fields on adjustable cerebrospinal fluid shunt valves. Surg Neurol 2005;63:467-68

35. Schneider T, Knauff U, Nitsch J, et al. Electromagnetic field hazards involving adjustable shunt valves in hydrocephalus. J Neurosurg 2002;96:331-34

36. Lavinio A, Harding S, Boogaard FV, et al. Magnetic field interactions in adjustable hydrocephalus shunts. $J$ Neurosurg Pediatr 2008;2:222-28

37. Strahle J, Selzer BJ, Muraszko KM, et al. Programmable shunt valve affected by exposure to a tablet computer. J Neurosurg Pediatr 2012;10:118-20

38. Anderson RC, Walker ML, Viner JM, et al. Adjustment and malfunction of a programmable valve after exposure to toy magnets: case report. J Neurosurg 2004;101(2 suppl):222-25

39. Turner SG, Hall WA. Programmable shunt-related suicide attempt. Acta Neurochir (Wien) 2006;148:1307-10, discussion 1310

40. Kataria R, Kumar V, Mehta VS. Programmable valve shunts: are they really better? Turk Neurosurg 2012;22:237-38

41. Lavinio A, Harding S, Boogaard FVD, et al. Magnetic field interac- tions in adjustable hydrocephalus shunts. J Neurosurg Pediatrics 2008;2:222-28

42. Frank E, Buonocore $M$, Hein L. Magnetic resonance imaging analysis of extremely slow flow in a shunt model system. Childs Nerv Syst 1992;8:73-75

43. Gideon P, Stahlberg F, Thomsen C, et al. Cerebral fluid flow and production in patients with normal pressure hydrocephalus studied by MRI. Neuroradiology 1994;36:210-15

44. Lee JH, Lee HK, Kim JK, et al. CSF flow quantification of the cerebral aqueduct in normal volunteers using phase contrast cine MR imaging. Korean J Radiol 2004;5:81-86

$\overline{\text { EDITORIAL }}$

\section{Multisociety Consensus Quality Improvement Guidelines for Intra-Arterial Catheter-Directed Treatment of Acute Ischemic Stroke: Implications for Neuroradiology and Stroke Centers}

\section{J.J. Connors \\ C.M. Black}

n 2001, the leadership of the American Society of Neuroradiology (ASNR), the Society of Interventional Radiology (SIR), and the Society of NeuroInterventional Surgery (SNIS, formerly the American Society of Interventional and Therapeutic Neuroradiology) wrote an official statement asserting that our members were capable of treating stroke with appropriate and adequate training. ${ }^{1}$ Now, more than a decade later and in the wake of significant advancement of endovascular (intra-arterial [IA]) techniques, it is mandatory that quality standards exist for the IA treatment of stroke. For this reason, the ASNR joined an international multisociety writing group to delineate these standards. The "Multisociety Consensus Quality Improvement Guidelines for Intraarterial Catheter-directed Treatment of Acute Ischemic Stroke" is now available on-line via hotlink provided in this issue of the American Journal of Neuroradiology.

The development and the evolution of IA stroke therapy have been controversial topics in various medical communities, and this therapy is still not universally accepted. Although thrombolysis is better than conservative therapy, ${ }^{2,3}$ modern thrombectomy devices have not yet proved to be clinically beneficial. In addition, IA stroke therapy is resource-intensive, emergent, and leads to good outcomes in perhaps only $50 \%$ of patients. As a result, IA treatment is not performed at many institutions. However, in the belief of these many international societies, for properly selected patients with large vessel occlusions, the outcomes for IA treatment are better than those from intravenous tPA alone. Furthermore, comprehensive stroke centers are required to offer this procedure because major benefit might be conferred to a significant proportion of patients with severe stroke. For this reason, quality improvement guidelines are both timely and necessary.

http://dx.doi.org/10.3174/ajnr.A3520 
These new multisociety performance and quality assurance standards feature several components: 1) clinical evaluation, imaging, and interpretation must be performed quickly, 2) intervention must be started and accomplished quickly and effectively, 3) hospital processes as well as angiographic and clinical outcomes must be measured, and 4) data must be consistently collected, complete, and submitted to a national registry.

Increasingly, good outcomes have been associated with careful patient selection, which, in turn, is informed by expeditious imaging and excellent interpretation. For example, some patients with a middle cerebral artery occlusion might have a National Institute of Health Stroke Scale score of 18, whereas others might have an NIHSS score of $8 .{ }^{4}$ However, only imaging reveals that they both have an MCA occlusion. The implications of an untreated (or inadequately treated) MCA occlusion can be devastating no matter the initial NIHSS. ${ }^{5,6}$ Multimodal imaging (CTA/ MRA, perfusion, diffusion) can reveal not only the anatomy and possible large vessel occlusion but also the physiology, functionality, and irreversibly damaged core versus threatened ischemic penumbra. Both the American Stroke Association "Guidelines for the Early Management of Patients with Acute Ischemic Stroke" 7,8 and "Recommendations for Imaging of Acute Ischemic Stroke" emphasize multimodal imaging and specifically noninvasive vascular imaging as key components of emergency treatment of stroke. Advanced multimodal imaging provides vital information concerning possible length of time to intervention and likelihood of a good clinical outcome. For this reason, imaging is a major component of emergency stroke treatment and an important component of the metrics defined in these guidelines. Neuroradiology can make a powerful contribution to stroke treatment and should take a leadership role in rendering accurate interpretations in an expeditious manner.

In these Quality Improvement Guidelines, all interventionists, no matter the specialty, are accountable to the same performance standards and are required to achieve acceptable clinical outcomes. Furthermore, all hospitals must track the processes of care for all emergency patients with stroke and the clinical outcomes on every patient treated to document and monitor the overall quality of patient care. Accordingly, these new standards require tracking and documentation of procedural events such as doorto-CT time as well as angiographic and 90-day clinical outcomes. The writing group identifies separate institutional metrics (such as door to CT) versus personal performance metrics. For example, "time to puncture" is a measure of the hospital's ability to actually move a patient from emergency department triage to imaging to the procedure suite and to prepare the patient for angiography. Although this aspect of care is not under the direct control of the interventionist, it is vital to achieving good outcomes and is therefore tracked as a series of separate measures. However, once the procedure has started, expeditious technique and satisfactory performance is then in the hands of the interventionist and is measured as "time from puncture to start of revascularization" as well as the ultimate revascularization success. The final summary end point for the entire process is the mandatory 90-day modified Rankin Scale score.

Data collection is essential to documenting and ultimately improving outcomes for all forms of stroke treatment, including IV
tPA as well as IA stroke therapy. Most of the defined metrics relate to expeditious processes, imaging, and transport and are just as applicable to quality care in Primary Stroke Centers as well as Comprehensive Stroke Centers. Whereas a local hospital data base may partially meet this need, a national registry has the capacity to provide uniform analysis and subsequent anonymous comparison of multiple process and outcome metrics at different hospitals for both IV tPA and IA treatments. For these reasons, and in uniform agreement with all medical societies, organizations, and accreditation agencies, use of a national registry is mandated in these guidelines. For any stroke center, the use of a national registry requires resources and possibly a change in approach. However, the requirement is clear. Accrediting agencies such as the Joint Commission and Det Norske Veritas Health Care follow the requirements of the Brain Attack Coalition ${ }^{10,11}$ concerning tracking processes of care, clinical outcomes, and the use of a registry. Furthermore, to clarify this requirement, the American Stroke Association specifically requires data collection by means of a national registry, not a local data base, and restates this in "Metrics for Measuring Quality of Care in Comprehensive Stroke Centers"12: "To facilitate data collection in a standardized way and to avoid the redundant efforts that would occur if CSCs designed their own databases, we expect that CSCs will make use of national databases or registries to collect data required for metrics and to collect additional detailed data that will assist in quality improvement..."; The Joint Commission reiterates that this concept applies to both primary stroke centers as well as comprehensive stroke centers. ${ }^{13}$ Many of these American Stroke Association data points are again stated in this current document while additional metrics are now specified, but again, all are mandated to be tracked in a national registry. A national registry provides opportunities for research as it records outcomes for large numbers of patients who were treated with multiple revascularization techniques, IV and/or IA. Because all forms of these therapies can be performed at both primary stroke centers as well as more advanced institutions, the repeated mandate for a national registry applies to both settings. All patients with stroke treated at both primary and comprehensive stroke centers should receive optimal care, have their processes of care tracked, quality measures monitored, and outcomes recorded.

For the ASNR, what do these standards represent? This is both a challenge and an opportunity. Neuroradiology has been involved in stroke care from its inception. More than 2 decades ago, interventional neuroradiologists pioneered IA stroke therapy. Today, neuroradiology is again taking a leadership role in ensuring the success of this clinical service in both imaging and procedural excellence. As providers of critical information that drives treatment decisions, we must provide rapid and accurate interpretations of complex neuroimaging. As interventionists, we must respond quickly with clinical and technical expertise and perform well not only as individual practitioners but as part of a complex hospital team. Finally, we must realize that documenting our processes of care and clinical outcomes is the key to improving our overall performance. These guidelines not only define what effective stroke treatment should look like but can also provide validation of each practitioner's performance. Ultimately, these guidelines provide a means to document a hospital's pro- 
cesses and subsequent success in providing quality stroke treatment and achieving good clinical outcomes for all patients with stroke, not just the few who receive IA therapy. For the good of our patients and the advancement of stroke treatment, it is the obligation of each practitioner and every hospital to uphold the guidelines as defined in this document.

\section{REFERENCES}

1. Emergency interventional stroke therapy: a statement from the American Society of Interventional and Therapeutic Neuroradiology Stroke Task Force of the American Society of Neuroradiology and the Society of Cardiovascular and Interventional Radiology. AJNR Am J Neuroradiol 2001;22:54

2. Lee M, Hong K-S, Saver JL. Efficacy of intra-arterial fibrinolysis for acute ischemic stroke: meta-analysis of randomized controlled trials. Stroke 2010;41:932-37

3. Lisboa RC, Jovanovic BD, Alberts MJ. Analysis of the safety and efficacy of intra-arterial thrombolytic therapy in ischemic stroke. Stroke 2002;33:2866-71

4. Maas MB, Furie KL, Lev MH, et al. National Institutes of Health Stroke Scale score is poorly predictive of proximal occlusion in acute cerebral ischemia. Stroke 2009;40:2988-93

5. Manelfe C, Larrue V, von Kummer R, et al. Association of hyperdense middle cerebral artery sign with clinical outcome in patients treated with tissue plasminogen activator. Stroke 1999;30:769-72

6. Tomsick T, Brott T, Barsan W, et al. Prognostic value of the hy- perdense middle cerebral artery sign and stroke scale score before ultraearly thrombolytic therapy. AJNR Am J Neuroradiol 1996;17:79-85

7. Adams HP, del Zoppo G, Alberts MJ, et al. Guidelines for the early management of adults with ischemic stroke. Circulation 2007; 115; 478 - e534

8. Jauch EC, Saver JL, Adams HP, et al. Guidelines for the early management of patients with acute ischemic stroke: a statement for healthcare professionals from the American Heart Association/ American Stroke Association. Stroke 2013;44:870-947

9. Latchaw RE, Alberts MJ, Lev MH, et al. Recommendations for imaging of acute ischemic stroke. Stroke 2009;40:3646-78

10. Alberts MJ, Latchaw RE, Selman WR, et al. Recommendations for comprehensive stroke centers: a consensus statement from the Brain Attack Coalition. Stroke 2005;36:1597-618

11. Alberts MJ, Latchaw RE, Jagoda A, et al. Revised and updated recommendations for the establishment of primary stroke centers: a summary statement from the Brain Attack Coalition. Stroke 2011;42:2651-65

12. Leifer D, Bravata DM, Connors JJ, et al. Metrics for measuring quality of care in comprehensive stroke centers: detailed follow-up to Brain Attack Coalition Comprehensive Stroke Center Recommendations. Stroke 2011;42:849-77

13. Joint Commission. Recording of the July 17, 2012 Comprehensive Stroke Center Certification webinar. Available at: http://www. jointcommission.org//recording_071712_csc_webinar/. Accessed November 18, 2012 